\title{
NARRARSE A SÍ MISMO: RESIDUO MODERNO EN LA HERMENÉUTICA DE PAUL RICOEUR
}

\section{MANUEL ALEJANDRO PRADA LONDOÑO ${ }^{1}$}

"Sentí, en la última página, que mi narración era un símbolo del hombre que yo fui, mientras la escribía y que, para redactar esa narración, yo tuve que ser aquel hombre y que, para ser aquel hombre, yo tuve que redactar esa narración, y así hasta lo infinito"

Jorge Luis Borges (La búsqueda de Averroes).

Resumen: Este artículo se desarrolla en cuatro partes: en la primera planteamos la crítica de Ricoeur a la filosofía del sujeto, inaugurada por Descartes, confrontada con la propuesta nietzscheana que considera engañoso el lenguaje por el cual puede decirse sujeto; en la segunda se muestra la posibilidad de hablar de identidad personal a partir de la construcción de una trama; en tercera instancia afirmamos que hablar de identidad narrativa es reconocer la incapacidad que tiene el sujeto de captarse instantáneamente, lo cual permite a Ricoeur sostener que su planteamiento puede denominarse ontología quebrada; las tres primeras partes siguen a Ricoeur con cierta "fidelidad". El cuarto apartado es un conjunto de preguntas, a propósito de los planteamientos ricoeurianos esbozados, que han ido mostrando su pertinencia en el transcurso de nuestras investigaciones sobre nuevas narrativas en ciencias sociales.

Palabras clave: Sujeto, identidad personal, identidad narrativa, trama, concordancia, discordancia, lenguaje.

Abstract: This article is developed in four parts. In the first one, criticism by Ricoeur of the philosophy of subject, inaugurated by Descartes, is outlined and confronted with Nietzs che's proposal that considers that the language by means of which subject can be said is deceiving. In the second one, the possibility of speaking of personal identity, derived from the construction of a plot, is shown. In the third part, it is stated that speaking of narrative identity is to recognize the inability that the subject has of capturing himself instantly, which allows Ricoeur to argue that his position can be denominated broken ontology. These first three parts follow Ricoeur with certain "fidelity." The fourth section is a group of questions concerning the sketched ricoeurian positions, which have been showing its relevancy in the develpment of our research on new narratives in social sciences.

\footnotetext{
${ }^{1}$ ProfesorUniversidad PedagógicaNacional 
Key words: Subject, personal identity, narrative identity, plot, agreement, disagreement, language.

\section{El planteamiento ricoeuriano frente a las filosofías del sujeto}

Para comenzar a situar el planteamiento ricoeuriano sobre la identidad narrativa, considero que deben ponerse en consideración las críticas de Ricoeur a Descartes, como fundador de las llamadas filosofías del sujeto.

La primera problemática se refiere a que la duda de Descartes no es una duda desesperanzada, sino que, por el contrario, hace de sí misma su horizonte y quiere convencerse de la existencia de un fundamento último. Por eso, la primera certeza que de ella se deriva es la existencia, implicada en el ejercicio mismo del pensamiento (en primera instancia, dubitativo). No obstante, podría preguntarse: ¿el que duda es necesariamente "alguien" corporal, de carne y hueso, con un referente espacio-temporal? Ricoeur responde negativamente. Es un yo sin anclaje, no es nadie. Según Ricoeur, aquí se reduce el sujeto al acto más simple y escueto que es el de "pensar". Además, en la duda ya está implicado el sujeto: sólo debía sacarse a la luz mediante una sentencia como la que inmortalizaría a Descartes (cogito, ergo sum).

Pero la pregunta por el quién de la duda, unida a la del quién del pensamiento, reviste dos nuevas cuestiones: ¿quién existe? y ¿qué es eso que existe?, cuando Descartes afima: "Mientras yo piense, soy algo".

Con la pregunta por el qué del sujeto, Descartes llega a la fómula: "No soy más que una cosa que piensa, un espíritu, un entendimiento, una razón. (...) Una cosa que duda, entiende, afima, niega, quiere o no quiere, imagina o siente"

A esta enumeración de lo que Descartes considera la respuesta a las preguntas por el quién de la duda y del pensamiento y por el qué de los mismos, replica Ricoeur: "La identidad de (este) sujeto no puede tratarse más que de la identidad en cierto sentido puntual, ahis tórica, del 'yo' en la diversidad de sus operaciones; esta identidad es la de un 'mismo' que escapa a la altemativa de la permanencia y del cambio en el tiempo, puesto que el cogito es instantáneo"3.

Esta dificultad va a provocar, en último término, la pérdida de la pregunta por el quién del pensamiento y, mucho más: "La problemática del sí resulta magnificada, pero a costa de perder su relación con la persona de la que se habla, con el yo-tú

\footnotetext{
${ }^{2}$ DESCARTES, Rene. Méditations métaphysiques. Paris, Garnier-Flammarion, 1979; p. 22.

${ }^{3}$ RICOEUR,Paul. Si mismo como otro. México, Siglo XXI editores, 1996; p. XVIII. 
de la interlocución, con la identidad de una persona histórica, con el sí de la responsabilidad", .

En los años posteriores a los planteamientos de Descartes, David Hume mostró serias dudas sobre la posibilidad de conocer -acaso sobre la "existencia" - de "algo" a lo cual pudiera llamárs ele yo o sujeto. Hume exige para cada idea una impresión correspondiente; y como no encuentra en el examen de su "interior" más que una diversidad de experiencias y ninguna impresión invariable relativa a la idea de un sí, concluye que esta última es una ilusión. Luego de considerar esta dificultad, Hume puede preguntarse: "¿qué nos inclina a superponer una identidad a estas percepciones sucesivas, y a suponer que estamos en posesión de una existencia invariable e ininterrumpida durante todo el curso de nuestras vidas?" (SO 123). La respues ta será: la imaginación, a la cual se le atribuye "la facultad de pasar con facilidad de una experiencia a otra si su diferencia es débil y gradual, y así transfomar la diversidad en identidad" (SO 124); y la creencia, que llena el déficit de la impresión.

Pero la más dura crítica a las filosofías del sujeto fue lanzada por Friedrich Nietzsche. La primera, frente a la tradición filosófica con pretensiones de autofundamentación, tiene como punto neurálgico el lenguaje: la filosofía de la subjetividad ha hecho abs tracción de la mediación lingüís tica con la que ha podido decir concluyentemente yo soy y yo pienso, olvidando los recursos retóricos (ocultos) en nombre de la inmediatez de la reflexión.

Nietzsche, en Verdad y mentira en sentido extramora $F$, lleva hasta las últimas consecuencias su sospecha radical en el lenguaje. Sostiene allí que todo lenguaje es figurado y, por ello, mentiroso.

El yo pienso no puede sustraerse al lenguaje mentiroso, como tampoco puede hacerlo la realidad formal de las ideas, ni su valor representativo. Por esta razón es que señala Ricoeur que Nietzsche quiere ser el "genio maligno" aun más engañador y más incisivo que el genio de Descartes.

Podríamos citar, a manera de ejemplo, uno de los fragmentos que figuran en La voluntad de poder:

Si nuestro 'yo' es para nosotros el único ser confome al cual hacemos y comprendemos todo ser. ¡muy bien! Entonces es muy pertinente la duda de si no se presenta aquí una ilusión perspectivista: la unidad aparente, en la que todo converge como en un horizonte (VP 518). El origen de las 'cosas' es por completo la obra de los que imaginan, de los que piensan, quieren, inventan. (...) Incluso el 'sujeto' es algo creado de esta forma, una 'cosa' como todas las otras (VP 556).

${ }^{4}$ Ibid., p. XXII.

${ }^{5}$ NIETZSCHE, Friedrich. "Verdad y mentira en sentido extramoral”. En: El libro del filósofo. Madrid, Ed. Taurus, 1974;pp. 85-108.

${ }^{6}$ NIETZSCHE, Friedrich. Fragmentos póstumos. Bogotá, Ed. Norma, 1997; pp. $92-93$. 
Dos puntos aquí pueden anotarse, a manera de conclusiones de lo que Ricoeur considera la crítica fundamental de Nietzsche a las filosofías del sujeto:

- No existen "los hechos" del mundo exterior, sino tan sólo interpretaciones.

- $\quad$ El cogito no se escapa de ser una interpretación más de aparentes hechos fenoménicos de lo que denominamos - metafóricamente- mundo interior. El "yo" no es inherente al cogito, sino una interpretación que relaciona un supues to sujeto con una acción a la que se ha llamado "pensamiento", que no es más que un orden aparente.

Finalmente, Ricoeur considera que Nietzs che ha hecho un ejercicio de duda hiperbólica, tratando de decir: Dudo mejor que Descartes porque he dudado de la duda misma. Además, ha querido mostrar que el sujeto no es más que multiplicidad, todo dentro de la hipótesis de un engaño terrible en el lenguaje.

En Sí mismo como otro (SO), Ricoeur se propone mostrar que el yo no es inmediato, ni puede colocarse como último fundamento. El sujeto que trata de sacar a la luz no es el sujeto de las filosofías que lo exaltan ni el de las filosofías que lo hacen desaparecer con la más dolorosa humillación. La reflexión de Ricoeur sobre el sujeto lo ha llevado a considerar que "no hay una aprehensión del propio ser en el acto del pensamiento. Hay un hiato, una distancia (y ciertamente no una distancia cualquiera) entre mi conciencia inmediata y mi propio ser efectivo, real"'.

Es por ello que Ricoeur considera tan cercano a J. Greish, ya que éste afima que nuestro tiempo puede considerarse como la edad hemenéutica de la razón ${ }^{8}$, en cuanto el hombre es un ser anclado en el lenguaje, un ser eminentemente simbólico y, por tanto, susceptible de ser interpretado; as imismo, porque ins inúa la imposibilidad de sentar un fundamento último: la palabra hemenéutica, según la perspectiva ricoeuriana, despoja al "yo" de su gloria, a la vez que conforta su arrojo de existir.

\section{La identidad narrativa como construcción de una trama}

Atendiendo a las indicaciones que ofrecen la hemenéutica y la fenomenología sobre el lenguaje como estructura de nuestro ser-en-el-mundo y, por ende, como condición de posibilidad del acceso al sujeto, gran parte de la obra ricoeuriana se ha ocupado de hacer visibles los tejidos lingüísticos, en sus dimensiones argumentativa, retórica y poética, insertos en la cotidianidad.

Las dimensiones señaladas por Husserl, Heidegger y Gadamer: mundo de la vida, dasein, tem poralidad, lenguaje, interpretación, entre otras, se constituyen en los hilos conductores del planteamiento ricoeuriano. En este apartado se pretende

\footnotetext{
${ }^{7}$ CALVO MARTÍNEZ, Tomás. "Del símbolo al texto". En: CALVO, Tomás y ÁVILA, Remedios. Paul Ricoeur: los caminos deinterpretación. Granada, Ed. Ánthropos, 1991; p. 117.

${ }^{8}$ GREISH, Jean. L'age herméneutique de la raison. Paris, Ed. du Cerf, 1985. 
ver la relación establecida por Ricoeur entre la temporalidad, que dificulta una respuesta inmediata a la pregunta por el sujeto desde una visión que podría ser tildada de "esencialista", y la narración, como construcción de una trama, medio que hace emerger la identificación de un quién en medio del cambio y la contingencia.

El primer propósito de Ricoeur en el estudio VI de SO, titulado El sí y la Identidad Narrativa, será mostrar "cómo el modelo específico de conexión entre acontecimientos constituidos por la construcción de la trama pemite integrar en la permanencia en el tiempo lo que parece ser su contrario bajo el régimen de la identidad-mismidad, a saber, la diversidad, la variabilidad, la discontinuidad, la inestabilidad" (SO. 139).

Ricoeur muestra que la identidad comprendida narrativamente puede llamarse identidad del personaje, la cual se constituye en unión íntima con la identidad de la trama.

¿Qué es construir una trama? Es lo mismo que poner en intriga (en francés, mise en intrigue). El entramado de la acción cons is te, básicamente, en la síntesis de dos elementos heterogéneos: concordancias y discordancias.

Por concordancia entiendo el principio de orden que vela por lo que Aristóteles llama 'disposición de los hechos'. Por discordancia entiendo los tras tocamientos de fortuna que hacen de la trama una transfomación regulada, des de una situación inicial hasta otra terminal. Aplico el término de configuración a este arte de la composición que media entre concordancia y discordancia (SO. 139-140).

De la concordancia dependen, obviamente, la definición misma de mythos como composición de las acciones y los corolarios de esta definición, a saber, la unidad, la marca de un comienzo, de un medio y de un fin, la amplitud y la conclusión. Pero la concordancia tiene su reverso; 'discordancia o inversión' de la dicha en desdicha, cambio de fortuna (...), reconocimiento inesperado, incidentes que espantan o inspiran piedad, efectos violentos".

La propuesta de Ricoeur no se limita a presentar separados dos conceptos divergentes, sino que apunta a la posibilidad (necesidad) de asumirlos juntos, como concordancia discordante, que es la mediación que hace la trama entre "la diversidad de acontecimientos y la unidad temporal de la historia narrada (...); entre la pura sucesión y la unidad de la forma temporal" (SO. 140). Es por ello que no se entiende la discordancia como algo exterior a la concordancia. Al contrario, en aras de una plena "inteligencia narrativa", consistente en la asunción de dicha síntes is aparentemente paradójica, deberá incorporarse la discordancia a la concordancia, "conseguirse que la sorpresa contribuya al efecto de sentido que,

\footnotetext{
${ }^{9}$ RICOEUR, Paul. "Relectura de la Poética de Aristóteles". En: VALDÉS, Mario y OTROS. Con Paul Ricoeur: indagaciones hermenéuticas. Barcelona, Aull Editorial, 2000;pp. 146-147. 
con posterioridad, hace que la fábula (mythos) aparezca como veros ímil, incluso necesaria"

Hace su aparición en el escenario el problema del acontecimiento. Con Donald Davidson, en su obra Essays on actions and events ${ }^{11}$, se había puesto en duda que el acontecimiento, en cuanto ocurrencia, tuviera derecho a un estatuto ontológico o pudiera cons tituir el objeto de una descripción impersonal.

¿Qué es lo que hace, en cambio, que un acontecimiento se vuelva importante, desde su propia contingencia? El acontecimiento es lo inesperado, lo sorprendente, pero se convierte en parte integrante de la his toria cuando se mira en la perspectiva de la totalidad temporal llevada a su témino. Se convierte, entonces, en necesario, siendo paradójicamente contingente:

La inversión del efecto de contingencia en efecto de necesidad se produce en el corazón mismo del acontecimiento: en cuanto simple ocurrencia, este último se limita a frustrar las expectativas creadas por el curso anterior de los acontecimientos; es simplemente lo inesperado, lo sorprendente; sólo se convierte en parte integrante de la historia cuando es comprendido después, una vez transfigurado por la necesidad, de alguna forma indirecta, que procede de la totalidad temporal llevada a su término. $Y$ esta necesidad es una necesidad narrativa cuyo efecto de sentido procede del acto configurador como tal (SO. 141).

Reforzando esta idea, en Autocomprensión e historia afima que "la acción de intrigar es también una síntesis de lo heterogéneo, por el hecho de que una disposición de los hechos en una historia contada extrae de un polvo de acontecimientos un relato unificado"12. O como explica en otra parte: "el poner en intriga es una suerte de innovación semántica pues, en su dinamismo, reúne en una historia unitaria incidentes heterogéneos, transforma en historia los acontecimientos dispersos y, recíprocamente, extrae la historia narrada de esos acontecimientos"

Un paso adelante. Para concebir narrativamente la identidad personal es necesario pasar de la configuración de acciones a la adscripción de acciones a personajes, es decir pasar del ¿qué?, propio de la mismidad, al ¿quién? de la ipseidad. Se distingue una correlación muy estrecha (casi subordinada) entre personaje y acción: "Es en la historia narrada, con sus características de unidad, de articulación interna y de totalidad, conferidos por la operación de construcción de la trama, donde el personaje conserva, a lo largo de toda la historia, una identidad correlativa a la de la historia misma" (SO 142).

\footnotetext{
${ }^{10}$ Ibid., p. 147.

${ }^{11}$ Oxford, Claredon Press, 1980.

${ }^{12}$ RICOEUR,Paul. “Autocomprensión e historia”. En: CALVO, Tomás y ÁVILA, Remedios. Op. cit., p. 38.

${ }^{13}$ RICOEUR, Paul. "La vida: un relato en busca de narrador". En: Educación y política. De la historia personal a la comunión de libertades. Buenos Aires: Docencia, 1984; p. 38-39.
} 
Terminada la primera parte de la exposición sobre la identidad del personaje y de la trama, concluye Ricoeur que es en el relato donde se puede atribuir el qué de la acción a un quién, y más aun, desarrollarse otro tipo de interrogantes como el ¿por qué? y el ¿cómo? de las acciones mismas. Sobre esto, afima que "la persona (...) comparte el régimen de la identidad dinámica propia de la historia narrada. El relato construye la identidad del personaje, que podemos llamar su identidad narrativa, al construir la de la historia narrada. Es la identidad de la historia la que hace la identidad del personaje" (SO. 147).

De la correlación entre acción y personaje del relato se deriva una dialéctica interna al personaje, punto más alto de la dialéctica entre discordancia y concordancia desplegada en la cons trucción de la trama de la acción. Ahora bien, ¿en qué cons iste esa dialéctica? Aunque ya habíamos hablado de ello cuando nos referíamos a la concordancia discordante, cabe anotar un aspecto más de dicha correlación.

La dialéctica consiste en que, según la línea de concordancia, el personaje saca su singularidad de la unidad de su vida considerada como la totalidad temporal singular que lo distingue de cualquier otro. Según la línea de discordancia, esta totalidad temporal está amenazada por el efecto de ruptura de los acontecimientos imprevisibles que la van señalando (encuentros, accidentes, etc.); la síntesis concordante-discordante hace que la contingencia del acontecimiento contribuya a la necesidad en cierto sentido retroactiva de la historia de una vida, con la que se iguala la identidad del personaje. Así el azar se cambia en destino. Yla identidad del personaje, que podemos decir 'puesto en trama', sólo se deja comprender bajo el signo de esta dialéctica (SO. 147).

\section{La propuesta ricoeuriana de la ontología quebrada}

¿Qué tipo de ser es el ente que llamamos yo? Si ya no se trata de pretender una autofundación absoluta, al modo de las filosofías del cogito, entonces, ¿qué seguridad nos deja hablar de identidad narrativa? La respuesta es: jninguna! No podemos hablar de una seguridad infranqueable, indubitable o absoluta. El nuevo saber que se nos proporciona es el de la atestación, gracias al cual "sabemos de seres que actúan y que sufren, que pueden empeñarse en una promesa, amar y recibir amor de otra persona"14.

Por tanto, la ontología que nos corresponde no puede ser otra que una ontología "militante y rota". Decimos "rota" en el sentido que toma Le conflit des interprétations: es una ontología no separable de la interpretación, por lo tanto, una ontología que reconoce como único acceso al ser, como la única manera de hablar de él, la forma que adopta la hemenéutica. Más aún, la ontología es comparable con la imagen de Moisés y de la tierra prometida. "Se puede bien decir que la ontología es la tierra prometida para una filosofía que comienza con el

\footnotetext{
${ }^{14}$ JERVOLINO, Domenico. L'amore difficile. Rom, Ed. Studium, 1995; p. 31. 
lenguaje y la reflexión; pero, como Moisés, el sujeto que habla y reflexiona puede sólo divisarla antes de morir"15.

Entonces, si la ontología está en manos de la interpretación, decir "identidad", más si se califica de "narrativa", es reconocer la imposibilidad de una aprehensión inmediata y directa de sí por sí mismo. Ricoeur acude al recuerdo de algunos criterios sobre la hermenéutica que ayudan a comprender mejor el papel que se le da a un tipo de reflexión sobre la identidad que se funde con la retórica, la poética, la literatura, el arte.

- $\quad$ Puesto que no es posible una hermenéutica única y universal, cada hermenéutica descubrirá aquel aspecto de la existencia que la funde como método. Ricoeur ha acudido a la narración como modelo de aprehensión del seren-el-mundo.

- $\quad$ El hombre sólo se puede referir a lo real a través de la simbolización del lenguaje, pero siempre será una referencia parcial y limitada. Tal función simbólica es, en consecuencia, una condición de posibilidad de un yo significativo, ya que sólo siguiendo la dinámica de los símbolos que nosotros mismos utilizamos, podremos acceder a parcelas (ontológicas) difícilmente alcanzables por otros medios $^{16}$.

Por tanto, bajo el presupuesto de que somos seres-dichos, seres que se dicen, seres de los que se puede decir algo, inscribimos la pregunta ¿quién soy yo? en el requerimiento de las mediaciones simbólicas y culturales. "La meditación sobre el ser de la existencia tiene lugar como hermenéutica: pasando por una hermenéutica la filosofía reflexiva sale de la abstracción y encuentra en la interpretación de signos el camino largo de la toma de conciencia"17.

Ahora bien, ¿qué tendría que decir una propuesta de este tipo a los filósofos y a la Filosofía? Quizás se haya olvidado que el mundo es una interpretación hecha por nosotros, y que, por ser interpretación, la filos ofía no riñe nunca con la poética, con la metáfora, con la narración, con la retórica. Quizás, también, se esté invitando a considerar en un tono más moderado (humilde, si se quiere) el trabajo filosófico, "sin pretender lecturas absolutas o totalitarismos, porque (la filosofía) ha aprendido que la realidad y la verdad están abiertas a múltiples interpretaciones y, que, en última instancia, más que una realidad o una verdad existe una variedad de discursos que las constituyen y explican"18.

\footnotetext{
${ }^{15}$ RICOEUR,Paul. Le conflit des interprétations: essais d herméneutique. Paris, Ed. Seuil, 1969; p. 28.

${ }^{16}$ Cf. MACEIRAS, Manuel. "Paul Ricoeur. una ontología militante". En: CALVO, Tomás y ẢVILA, Remedios. $O p$. cit.,pp. 52-53.

${ }^{17}$ NAVARRO, Juan Manuel. "Existencia y libertad: sobre la matriz ontológica del pensamiento de Paul Ricoeur". En: CALVO y ÁVILA. Op. cit., p. 152.

${ }^{18}$ MONASTERIOS, Elizabeth. "Poesía y filosofia: el aporte de Paul Ricour al estudio de la metá fora". En: VALDÉS, Mario y OTROS. Op. cit., p. 53.
} 


\section{Cuestiones en discusión}

Hasta aquí puede haberse presentado un panorama general de la narración de sí mismo como construcción de una trama, frente a las pretensiones autofundantes de las filosofías del sujeto; asimismo, se ve con claridad la importancia que reviste el lenguaje en la construcción de la identidad personal por medios narrativos. ¿Qué residuos de modernidad se resguardan en esta propuesta?

a.

En primer lugar, la preocupación por el sujeto. Ciertamente Ricoeur intenta mediar entre las filosofías que lo exaltan y las que lo someten a humillación, pero apuesta más por la exaltación narrativa, en una confianza acendrada en el lenguaje. ¿Acaso, en última instancia, no sale airoso el sujeto -ya consciente de su temporalidad, de su finitud, de su mutabilidaden una suerte de dispositivo contra aquello que pone a prueba su identidad?

El narrador puede presentarse como una figura nueva del cogito cartesiano -esta afirmación puede convertirse en pregunta-: cuestiona las discordancias de los acontecimientos que advienen sin aviso, como señal de la contingencia humana que conlleva nuestra temporalidad, y las organiza, siempre en un discurso, de tal forma que resulte una unidad narrativa, emergente de la dispersión de la vida misma; exorciza la muerte y los vacíos de la memoria, acudiendo a principios narrativos que llegan como noticia de otros -quienes prestan su voz a nuestro relato e inmediatamente desaparecen- y a finales de episodios que nunca logran apresar la muerte, aunque sí pueden anticiparla ${ }^{19}$; acude a la memoria para "descubrir" el movimiento que lo llevó a ser quien es, luego de lo cual no le queda sino decir: "Amén" luego soy.

¿Salva la referencia a la temporalidad, asunto que invade la teoría narrativa del sí, el intento de hacer una nueva filosofía del sujeto que se funde a sí misma? Queda esto por discutir. Por ahora, digamos que el intento de poner en intriga un personaje se corresponde con la lucha que los seres humanos establecemos cuerpo a cuerpo contra nuestro ser-para-la-

\footnotetext{
19 “ La memoria se pierde en las brumas de la infancia. (...) El acto por el que he sido concebido pertenece más a la historia de los demás, en este caso [del nacimiento] de mis padres, que a mí mismo. Y la muerte sólo será final narrado en el relato de los que me sobrevivan" (SO 162).

20 "Se trata de la última mirada dirigida a una historia que se cierra como un libro, de la última palabra pronunciada al final de una vida que vuelve sobre sus propios pasos para decir: Así sea. Sí. Amén". (RICOEUR, Paul. "Función narrativa y experiencia humana del tiempo". En: Historia y narratividad. Barcelona, Ed.Paidós, 1999; p. 209). 
muerte, que se patentiza en nuestra experiencia temporal confusa, informe $y$, en el fondo, muda ${ }^{21}$; narrarse a sí mismo -o interpretarse en la lectura de obras literarias- tiene la virtud de "debilitar el aguijón de la angustia frente a la nada desconocida, dándole imaginariamente el contorno de tal o cual muerte, ejemplar por un motivo o por otro" (SO 164-165). ¿Podría vislumbrarse en la postura de Ricoeur una autofundación, ahora más consciente de sus limitaciones?

b.

En segundo lugar, si el cogito cartesiano es, según Ricoeur, ahistórico, el sí mismo que se narra no tiene anclaje topográfico. Quizá en este trabajo no nos detengamos en el problema espacial de la narración, pero valdría la pena que no pasara desapercibido. Garrido Domínguez afirma: "A primera vista el espacio desempeña dentro del relato un contenido puramente ancilar: es el soporte de la acción. Sin embargo, una consideración un poco más atenta revela de inmediato que el espacio en cuanto componente de la estructura narrativa adquiere enome importancia res pecto de los demás elementos, en es pecial, el personaje, la acción yel tiempo"22.

El mundo también es construcción, y construcción topológica, especialmente en el marco narrativo. Todo es contemplado desde una perspectiva y resulta imposible sorprender al objeto al margen del sesgo que el sujeto observador le imprime. La espacialidad se manifiesta en los relatos verbales desde los marcadores espaciales del idioma: a) en primer lugar, las pre-posiciones que, como su nombre indica, ubican, pre-ponen espacialmente; b) los sustantivos que están en una topología espacial abstracta o concreta, común o propia, pero siempre sustentando; c) los adjetivos, (ad-jectum: lo que está junto a otra cosa) sean nominales o verbales (adverbios) que marcan modificadores espaciales y se añaden a las cualificaciones sustantivas o verbales ; d) los verbos, que al establecer dynamis, movimiento, cambio, transformación, sitúan igualmente e implican un eje topológico.

C.

En tercer lugar, en la narración todavía no se vislumbra cómo el otro puede ser reconocido como sujeto que piensa, actúa y se narra con su propia $\mathrm{voz}^{23}$. Veíamos atrás que Ricoeur critica del cogito cartesiano su pérdida de la relación con la persona de la que se habla, con el yo-tú de la

\footnotetext{
${ }^{21}$ Cf. RICOEUR, Paul. Tiempo y relato I. Madrid, Ed. Cristiandad, 1987; p. 13.

${ }^{22}$ El Texto narrativo. Madrid, Ed. Síntesis, 1993; p. 207.

${ }^{23} \mathrm{Si}$ se sigue al mismo Ricoeur, la inclusión real del otro sólo tiene plena comprensión en el plano ético de la pregunta quién. El desarrollo de este asunto puede encontrarse claramente en los estudios VII, VIII y IX de SA.
} 
interlocución. El sujeto que se narra a sí mismo ¿incluye efectivamente al otro? ¿Puede reducirse su inclusión a la mención escueta? Nuestra respuesta es negativa. Estamos de acuerdo: somos coautores de nuestras narraciones, lo cual supone que otros han hecho con nosotros una historia que contar; incluimos personajes distintos a nosotros, a la manera de coprotagonistas de nuestra vida; sabemos de las imbricaciones que se tejen entre nuestras historias y las historias de los demás. ¿Nos "libran" estas minúsculas inclusiones discursivas de la urgencia moral suscitada por aquellos que no tienen cómo narrarse para ser oídos y alcanzar la posibilidad de hacer respetar sus derechos? Con nuestras narraciones, por ejemplo en ciencias sociales, en etnografía o en historia, por poner un ejemplo, los otros tienen que soportar, incluso padecer o sufrir nuestras interpretaciones sobre ellos ${ }^{24}$.

¿El lenguaje, aceptado como legado cultural y, por ende, comunitario, asegura que la narración del sí sea un recurso creador de sentido en posibilidades equitativas para todos? Tal vez sea oportuno escuchar a Habermas: "Los sujetos hablantes son, o bien señores o bien pastores de su sistema de lenguaje. O bien se sirven del lenguaje en términos de creación de sentido, para alumbrar innovadoramente su mundo, o bien se mueven ya siempre dentro del horizonte de la apertura o alumbramiento del mundo, que el propio lenguaje se cuida de efectuar para ellos"25. Se hace apremiante comprender que la narración requiere volver al diálogo entre dos sujetos igualmente capaces de alzar la voz.

d.

Otro asunto que queremos poner en consideración se refiere a lo que podría llamarse confianza en el lenguaje como estructura posibilitadora de la comprensión de sí. La propuesta ricoeuriana de la narración de sí mismo o de la autocomprensión en la lectura de obras de ficción se desarrolla en términos de discurso. Y a éste se le designa la responsabilidad de construir la unidad narrativa de una vida, es decir, una identidad personal.

\footnotetext{
${ }^{24}$ Sin embargo, Ricour advierte: "En realidad, omitir y soportar, induso padecer, sufrir, son tanto hechos de interacción como de comprensión subjetiva. Estos dos términos reauerdan que, tanto en el plano de la interacción como de la comprensión subjetiva, el no-obrar es también un obrar. no atender, dejar hacer, es también dejarque otro haga, a veces de forma criminal; en cuanto a soportar, es mantenerse uno mismo, de grado o por fuerza, bajo el poder de obrar de otro (...); soportar se convierte en padecer, que linda con sufrir. En este punto, la teoría de la acción se extiende desde los hombres actuantes a los hombres sufrientes" (SO. 158). Acaso las ciencias sociales puedan ayudar a que los sujetos marginados por interpretaciones foráneas se hagan conscientes de que su no-narrarse es condición de posibilidad de su marginalidad y de su desidentificación; pero, al tiempo, estén en capacidad las ciencias sociales- de suscitar mecanismos efectivos de participación, por medio delos cuales no sean más los quetomen la voz de los que han enmudecido, sino que, justamente, los que han carecido de voz comiencen a pronunciar su propio nombre.

${ }^{25}$ HABERMAS, Júrgen. El discurso filosófico dela modernidad. Buenos Aires, Ed. Taurus, 1989; pp. $376-377$. 
¿Puede apresar el lenguaje discursivo (oral o escrito) lo que soy yo mismo, íntimamente, o lo que es una comunidad, en sus dimensiones más originarias? ¿Puede suponerse que todo el fluir de acontecimientos, que tiñe nuestra vida de tan variado colorido, puede ser siempre puesto en un orden narrativo, en una trama? ¿No sentimos a veces que los acontecimientos de nuestra propia vida nos ponen frente a la limitación de nuestras estructuras lingüísticas? ${ }^{26}$.

La teoría en torno a la metáfora, desarrollada por Ricoeur especialmente en su obra La metáfora viva, nos hace notar la distancia que toma la hermenéutica de los lenguajes del positivismo y, en general, de la ciencia heredera de la Modernidad. En esta perspectiva la metáfora hace emerger sentidos insospechados que irrumpen en el letargo de nuestros discursos cotidianos.

No obstante los caminos que abre el lenguaje metafórico, podría afirmarse que no todo el fluir de nuestras vivencias está cimentado lingüísticamente. Todavía creemos que hay en nuestras experiencias, y aun en nuestra conciencia, un conjunto que clasificamos dentro de lo "inefable"; sin embargo, esa expresión es ya una confesión lingüística de la escasez de nuestras palabras; quizás decir "inefable" sea seguir girando en torno al fonocentrismo sin darle cabida a las amplísimas posibilidades de la gestualidad humana, tan rica en matices, o al arte, o a la mística. En todo caso, queremos insistir en que también es factible expresar nuestra identidad como sujetos, individuales y colectivos, a través de la imagen, de la música y, a veces, del silencio.

\footnotetext{
26 “ Todo evento es la vida misma que sobreviene en su ola plena, pero también es el signo de su abandono, del hecho de que hemos sido abandonados por el resplandor que nos ha herido y atravesado y que cada vez ha hecho de nosotros las víctimas señaladas de esta existencia, nosotros que nunca hemos nacido del todo, llamados de improviso a la vida y de la misma manera repentina vaciados de toda existencia" (GARGANI, Aldo Giorgio. "La copia y el original". En: VATTIMO, Gianni (Comp.). Hermenéutica y racionalidad. Bogotá, Ed. Norma, 1994; p. 93).
} 


\section{BIBLIOGRAFÍA}

RICOEUR, Paul. Le conflit des interprétations: essais d'heméneutique. Paris, Ed. Seuil, 1969.

RICOEUR, Paul. "La vida: un relato en busca de narrador". En: Educación y política. De la historia personal a la comunión de libertades. Buenos Aires: Docencia, 1984.

RICOEUR, Paul. Tiempo y relato I. Madrid, Ed. Cristiandad, 1987.

RICOEUR, Paul. Sí mismo como otro. México, Siglo XXI editores, 1996.

RICOEUR, Paul. Historia y narratividad. Barcelona, Ed. Paidós, 1999.

ÁVILA, Remedios y CALVO, Tomás. Paul Ricoeur: los caminos de interpretación. Granada, Ed. Ánthropos, 1991.

DESCARTES, Rene. Méditations métaphysiques. Paris, Garnier-Flammarion, 1979.

DESCARTES, Rene. Obras escogidas. 2a. edición. Buenos Aires, Ed. Charcas, 1980.

GARRIDO DOMínGUEZ, Antonio. El Texto narrativo. Madrid, Ed. Síntesis, 1993.

GREISH, Jean. L’age herméneutique de la raison. Paris, Ed. du Cerf, 1985.

HABERMAS, Júrgen. El discurso filosófico de la modernidad. Buenos Aires, Ed. Taurus, 1989.

JERVOLINO, Domenico. L'amore difficile. Roma, Ed. Studium, 1995.

NIETZSCHE, Friedrich. "Verdad y mentira en sentido extramoral". En: El libro del filósofo. Madrid, Ed. Taurus, 1974.

NIETZSCHE, Friedrich. Fragmentos póstumos. Bogotá, Ed. Noma, 1997.

VALDÉS, Mario y OTROS. Con Paul Ricoeur: indagaciones hemenéuticas. Barcelona, Azul Editorial, 2000.

VATTIMO, Gianni (Comp.). Hermenéutica y racionalidad. Bogotá, Ed. Norma, 1994. 